\title{
Correction to: association between internal migration and epidemic dynamics: an analysis of cause-specific mortality in Kenya and South Africa using health and demographic surveillance data
}

Carren Ginsburg ${ }^{1,2^{*}}$, Philippe Bocquier ${ }^{3,1}$, Donatien Béguy ${ }^{4}$, Sulaimon Afolabi ${ }^{1,2}$, Kathleen Kahn ${ }^{1,2,5}$, David Obor ${ }^{6}$, Frank Tanser ${ }^{7,8,9}$, Andrew Tomita ${ }^{7,10}$, Marylene Wamukoya ${ }^{4}$ and Mark A. Collinson ${ }^{1,2,11}$

\section{Correction to: BMC Public Health 18, 918 (2018)} https://doi.org/10.1186/s12889-018-5851-5

Following publication of the original article [1], the coauthors observed that Figure 8, although titled correctly, contained the same set of graphs as Figure 9. The correct Figure 8, depicting the competing risk models for the Kisumu HDSS, is presented below:

\begin{abstract}
Author details
${ }^{1}$ Medical Research Council/Wits Rural Public Health and Health Transitions Research Unit (Agincourt), School of Public Health, Faculty of Health Sciences, University of the Witwatersrand, 27 St Andrews Road, Parktown, Johannesburg 2193, South Africa. ${ }^{2}$ INDEPTH Network, Accra, Ghana. ${ }^{3}$ Centre de Recherches en Démographie, Université Catholique de Louvain, Louvain-la-Neuve, Belgium. ${ }^{4}$ African Population and Health Research Centre, Nairobi, Kenya. ${ }^{5}$ Umeå Centre for Global Health Research, Umeå University, Umeå, Sweden. ${ }^{6}$ KEMRI \& CDC - Centre for Global Health Research, Kisumu, Kenya. ${ }^{7}$ Africa Health Research Institute, University of KwaZulu-Natal, Durban, South Africa. ${ }^{8}$ Centre for the AIDS Programme of Research in South Africa (CAPRISA), Durban, South Africa. ${ }^{9}$ School of Nursing and Public Health, University of KwaZulu-Natal, Durban, South Africa. ${ }^{10}$ Nelson R Mandela School of Medicine, University of KwaZulu-Natal, Durban, South Africa.

${ }^{11}$ Department of Science and Technology/ Medical Research Council, South African Population Research Infrastructure Network, Johannesburg, South Africa.
\end{abstract}

The original article can be found online at https://doi.org/10.1186/s12889018-5851-5.

* Correspondence: carren.ginsburg@wits.ac.za

${ }^{1}$ Medical Research Council/Wits Rural Public Health and Health Transitions Research Unit (Agincourt), School of Public Health, Faculty of Health Sciences, University of the Witwatersrand, 27 St Andrews Road, Parktown, Johannesburg 2193, South Africa

${ }^{2}$ INDEPTH Network, Accra, Ghana

Full list of author information is available at the end of the article
Published online: 16 August 2021

\section{Reference}

1. Ginsburg, et al. Association between internal migration and epidemic dynamics: an analysis of cause-specific mortality in Kenya and South Africa using health and demographic surveillance data. BMC Public Health. 2018; 18:918. https://doi.org/10.1186/s12889-018-5851-5.

(c) The Author(s). 2021 Open Access This article is licensed under a Creative Commons Attribution 4.0 International License, which permits use, sharing, adaptation, distribution and reproduction in any medium or format, as long as you give appropriate credit to the original author(s) and the source, provide a link to the Creative Commons licence, and indicate if changes were made. The images or other third party material in this article are included in the article's Creative Commons licence, unless indicated otherwise in a credit line to the material. If material is not included in the article's Creative Commons licence and your intended use is not permitted by statutory regulation or exceeds the permitted use, you will need to obtain permission directly from the copyright holder. To view a copy of this licence, visit http://creativecommons.org/licenses/by/4.0/ The Creative Commons Public Domain Dedication waiver (http://creativecommons.org/publicdomain/zero/1.0/) applies to the data made available in this article, unless otherwise stated in a credit line to the data. 

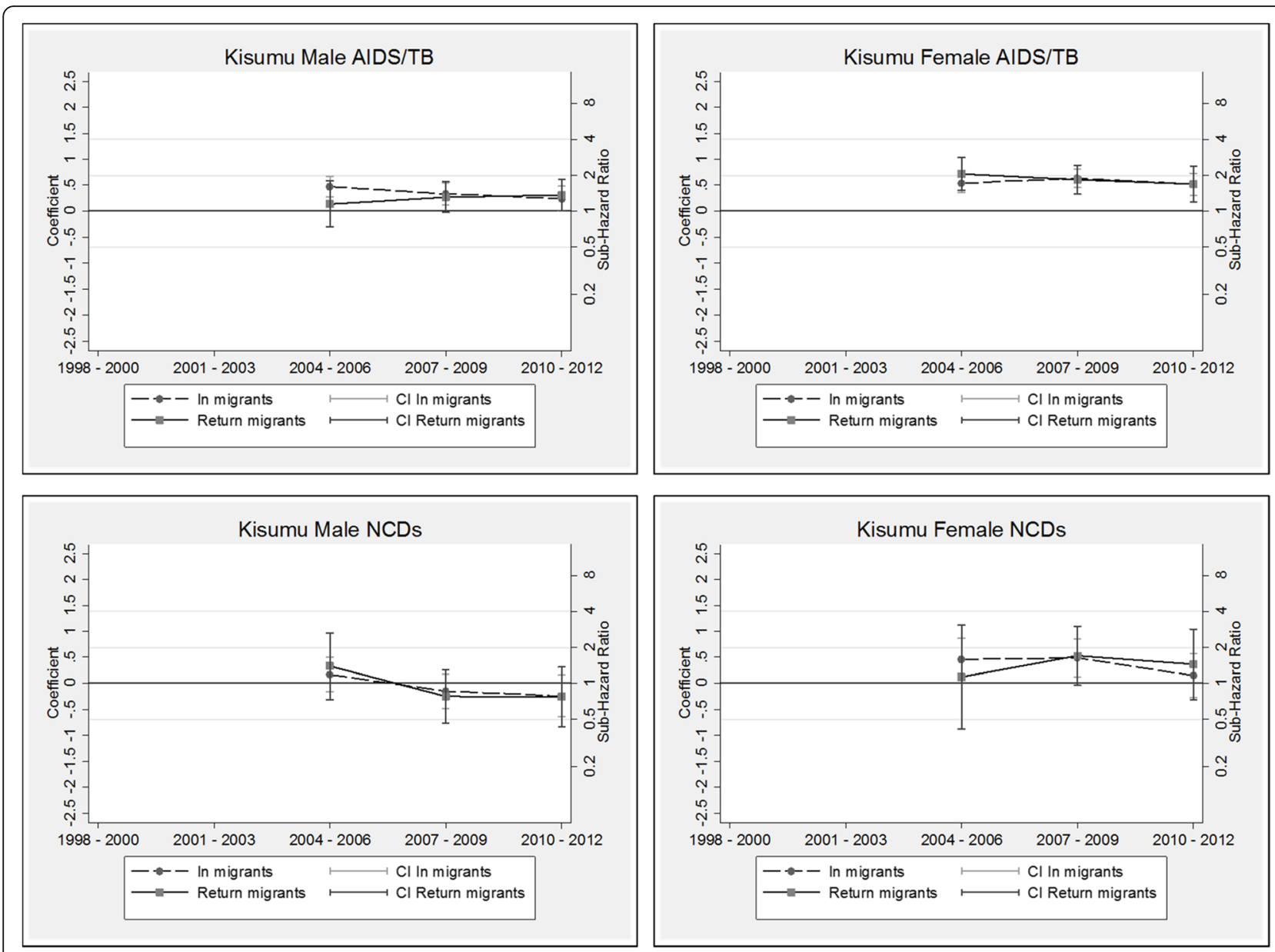

Fig. 8 Kisumu HDSS competing risk models 